Family : Nectariniidae

115. Purple-rumped Sunbird

116. Small Sunbird

117. Loten's Sunbird

118. Purple Sunbird

Family : Ploceidae

119. Yellow-throated Sparrow

120. House Sparrow

121. White-backed Munia

122. Black-headed Munia

123. Spotted Munia

Family : Fringillidae

124. Common Rosefinch

\section{A CASE OF OBSTRUCTIVE ASPHYXIA IN PYTHON (PYTHON MOLURUS)}

\section{P.K.Mehrotra ${ }^{1}$, Sudhir Bhargava ${ }^{2}$, Sheela Chaudhary ${ }^{3}$ and B.B.L.Mathur ${ }^{4}$}

${ }^{1}$ Officer Incharge Associate Professer, ${ }^{2}$ Instructor, ${ }^{3}$ Assistant Professor, Apex Centre, ARS Campus, Durgapura, Jaipur, Rajasthan, India

${ }^{4}$ Veterinary Officer, Zoo, Jaipur, Rajasthan, India

The Apex Centre, Jaipur received a carcass of python in the month of January 1998 from the Zoological Park, Jaipur. With the animal going off-feed during the winter months on account of hibernation, the zoo authorities apparently could not note of the deteriorating health condition of the snake. The general body condition of the carcass was good and the animal measured about 8 feet 6 inch in length. The carcass had no external marks of injury.

All the visceral organs presented white foci of variable size on the exposed surfaces. The gastro-intestinal tract when opened for examination, was found to be totally empty except for the presence of thick mucigenous mass in the posterior part of the intestine. The anterior part of small intestine had numerous round worms attached to the mucosa of the lumen. However, no pathognomonic lesions could be detected in the gastrointestinal tract.

The respiratory tract was explored from mouth to lung through

Received 22 July 1999;

Accepted 3 December 1999 trachea. About 6 inches posterior to mouth the lumen of trachea was found completely occluded with a mass of growth (more than 2 inches long). An incision on the mass revealed the presence of thick pus. Abscesses of variable sizes were found scattered throughout the trachea and in the lung. The lung was found to be totally collapsed. Heart was found empty.

The pus samples along with piece of lung and mucus from intestine were collected for further laboratory investigation. Gram's stained smears of the pus and impression smear of lung revealed the presence of Gram negative non-sporulated rods.

The pus sample was inoculated in blood agar medium. The bacterial growth appearing after incubation at $37^{\circ} \mathrm{C}$ for $24-36$ hours was subjected to purification by subculturing and generic identification tests as per usual microbiological techniques of identification (Carter, 1967). The bacterial isolate recovered from pus sample was identified as Corynibacterium (Actinomyces) pyogenes.

The mucus sample was inoculated in Mac Conkey and S S agar media. The bacterial growth appearing on the media were identified as Esteurichia coli, Proteus sp. and Salmonella sp.

The clinical history, post morten examinations and laboratory investigation were suggestive of obstructive asphyxia as the cause of death in the Python. Rao et al. (1980) reported concomittant occurrence of Corynibacterum pyogenes and Pseudomonas aruginosa in mouth lesions of cobra. Kaura et al. (1972), Sethi et al. (1980a\&b) and, Mishra and Verma (1981) have also reported the presence of enteric bacteria in python and other snakes.

\section{Acknowledgement}

The authors are thankful to Director Research (Veterinary and Animal Science), Rajasthan Agricultural University, Bikaner and Deputy Chief Wildlife Warden, Zoo, Jaipur for providing facilities.

\section{References}

Carter, G.R. (1967). Adv. Vet. Sci. Comp. Med. 11.321.

Kaura, Y.K., V.K. Sharma and I.P. Singh (1972). Snakes as reservoirs of Arizona and Salmonella. Zentrabl. Ba kteriol. 219: 506-13.

Mishra, H.N. and J.C. Verma (1981). Salmonella weltervedan from Cobra. Ind Vet. J. 58: 424

Rao, S.M., S. Zaki., T.S. Nalini and B.S. Keshavamurthy (1980). Concomittant occurrence of Corynibacterium pyogenes and Pseudomonas aruginosa in the mouth lesion of cobras. Curr. Sci. 49: 953.

Sethi, M.S., V.D. Sharma and S.P. Singh (1980a). Reservoirs of Zoonotic diseases of Uttar Pradesh. Technical Report PL 480 Grant No. F. GIN 550, G.B. Pant University and Tehnology, Pant Nagar, Nainital, U.P.

Sethi, M.S., V.D. Sharma and S.P. Singh (1980b). The occurrence of Salmonella in zoo animals in Uttar Pradesh and Delhi (India). Int. J. of Zoon. Dis. 7: 15-18. 